\title{
Técnica e Espontaneidade: uma comparação das obras de Jerzy Grotowski, Viola Spolin e Kristin Linklater
}

Autor: Thomas Holesgrove.

Instituição e tipo de vínculo: Universidade de São Paulo, Escola de Comunicação e Artes, doutorado.

Estágio da pesquisa: em andamento.

Área de estudo e nome do orientador: Pedagogia do Teatro, Prof. Dr José Batista dal Farra Martins (orientador)

Bolsa de fomento: CAPES

Atuação profissional: Artística; Cia. de Teatro, Arte Tangível / Instituição de ensino; Fábricas de Cultura.

Resumo: Este texto compara ideias sobre a relação entre a técnica e a espontaneidade, nas publicações de Jerzy Grotowski, Viola Spolin e Kristin Linklater. Os três autores escrevem sobre práticas muito diferenciadas, mas demonstram concordâncias significativas em relação às suas concepções da técnica e da espontaneidade. Desta maneira, o artigo defende a importância da técnica no trabalho criativo do ator, visando à criação de um processo experimental para o ensino/aprendizagem da voz.

Palavras chaves: aprendizagem, ensino, interpretação, teatro, voz

Title: Technique and Spontaneity: a comparison between the works of Jerzy Grotowski, Viola Spolin e Kristin Linklater.

Abstract: This text compares ideas about the relationship between technique and spontaneity in the publications of Jerzy Grotowski, Viola Spolin and Kristin Linklater. These three authors write about contrasting practices, but demonstrate significant agreement in relation to their conceptions of technique and spontaneity. In this manner, the article defends the importance of technique in the creative work of the actor, with the aim of creating an experimental process for teaching/learning voice.

Key words: acting, learning, teaching, theatre, voice

Titulo: Técnica y Espontaneidad: una comparación de las obras de Jerzy Grotowski, Viola Spolin y Kristin Linklater.

Resumen: Este texto compara ideas sobre la relación entre la técnica y la espontaneidad, en las publicaciones de Jerzy Grotowski, Viola Spolin y Kristin Linklater. Los tres autores escriben sobre prácticas muy diferentes, pero muestran concordancias significativas en relación a sus concepciones sobre técnica y espontaneidad. De esta manera, lo artículo defiende la importancia de la técnica y de la espontaneidad en lo trabajo creativo de lo actor, apuntando a la creación de un proceso experimental para la enseñanza/aprendizaje de la voz.

Palabras claves: aprendizaje, enseñanza, interpretación, teatro, voz 
A técnica, nas artes, hoje em dia, é frequentemente vista com suspeita, como algo que restringe a liberdade criativa, obrigando o sujeito a se conformar a moldes antigos, que não necessariamente servem na atualidade e que negam a possibilidade de um verdadeiro ato de criação. Outras vezes, a técnica é vista como algo seco e puramente mecânico, que não acrescenta muito às discussões sobre a estética ou sobre o processo criativo. Nesse contexto, o debate pode ser limitado à discussão sobre os males da técnica ou ser simplesmente encerrado, uma vez que a técnica é considerada como algo sem muita relevância no contexto contemporâneo.

No entanto, a técnica é o fundamento inescapável de qualquer atividade humana. A nossa "técnica" é o nosso "modo de fazer"; assim, recusar a discussão sobre a técnica simplesmente é negar a possibilidade de olhar criticamente para o nosso modo de fazer. A técnica artística deveria manter uma ligação íntima com a espontaneidade e a criatividade, mas, para desenvolver a técnica desta forma, é necessário investigar com profundidade a maneira como o artista adquire as habilidades específicas que servem à comunicação estética.

Desta maneira, surge o objetivo desse projeto de Doutorado: investigar diferentes processos do ensino/aprendizagem do ator, com o propósito de identificar princípios fundamentais ao desenvolvimento da técnica em conjunto com a espontaneidade, e aplicar estes princípios na criação de novos processos de ensino/aprendizagem da técnica vocal para o teatro.

Apresentamos aqui umas observações iniciais, destacando a importância da técnica no trabalho criativo do ator e da relação que a técnica deve manter com a espontaneidade.

O ponto de partida do projeto é a comparação das publicações de Jerzy Grotowski, Viola Spolin e Kristin Linklater, três autores que escrevem sobre práticas muito diferenciadas, mas que demonstram concordâncias significativas em relação às suas ideias fundamentais sobre técnica e espontaneidade. Grotowski situa-se no quadro referencial como um dos grandes mestres do teatro do século XX, ${ }^{\mathrm{i}}$ enquanto a obra de Spolin é uma referência importante para entender o valor do jogo em promover a espontaneidade no ensino teatral. A terceira referência, Kristin Linklater, é especialista em voz e introduz conceitos e práticas importantes em relação ao desenvolvimento da técnica vocal e da espontaneidade.

À primeira vista, cada uma desses autores mostra um nível de desconfiança sobre a ideia da "técnica" para o ator. Grotowski, por exemplo, escreve:

Não educamos um ator, em nosso teatro, ensinando-lhe alguma coisa: tentamos eliminar a resistência de seu organismo a este processo psíquico. O resultado é a eliminação do lapso de tempo entre o impulso interior e a reação exterior, de modo que o impulso se torna já uma reação exterior...Nosso caminho é uma "via negativa", não uma coleção de técnicas, e sim erradicação de bloqueios. (Grotowski, 1992, p.14-15) 
De modo comparativo, Viola Spolin adverte sobre os perigos da "técnica" também. Ela avisa:

\begin{abstract}
As técnicas não são artifícios mecânicos - um saco de truques bem rotulados para serem retirados pelo ator quando necessário. Quando a forma de uma arte se torna estática, essas "técnicas" isoladas, que se presume constituam a forma, estão sendo ensinadas e incorporadas rigidamente. (Spolin, 1998, p.12)
\end{abstract}

Finalmente, Kristin Linklater demonstra uma preocupação semelhante em relação à ideia da técnica vocal. Na apresentação do seu trabalho, explica:

O processo é estruturado para liberar a voz natural em vez de desenvolver uma técnica vocal. [...] A ênfase aqui é de remover bloqueios que restringem o instrumento humano como algo diferente do que o desenvolvimento de um instrumento musical habilidoso. (Linklater, 1976, p. 1).

Podemos ver, então, advertências sobre o perigo da técnica, repetidos pelos três autores. No entanto, seria errôneo dizer que qualquer um deles propõe que o ator trabalhe sem atenção à técnica. De fato, o próprio Grotowski, no mesmo ensaio citado acima, refere-se à "técnica cênica e pessoal do ator" como "a essência da arte teatral" (Grotowski, 1992, p.14). ii Spolin também não sugere que o ator deva dispensar a técnica, porém, ela defende que não se pode perder de vista que, antes de tudo, a técnica teatral deve servir à função da comunicação (Spolin, 1998, p.12). Nesse caso, seu trabalho com jogos teatrais visa ao desenvolvimento de um conhecimento intuitivo das técnicas de interpretação (Spolin, 1998, p.4). Enquanto isso, Linklater insiste na importância de "liberar" a voz de bloqueios, mas ainda reconhece o objetivo paralelo de "desenvolver um instrumento vocal condicionado, tonificado e afinado" (Linklater, 1976, p.111), e até faz referência ao seu trabalho como "uma técnica que usa a imaginação para unificar em um lugar no corpo, mente, sentimento, sopro e som" (Linklater, 1976, p.51).

Assim encontramos um paradoxo que exige atenção e entendimento para que não se despreze a importância fundamental da técnica no trabalho do ator, pensando-a como um elemento antagônico à criatividade. O que significa a desconfiança que esses três autores mostram em relação à técnica, e como é que deveríamos ler suas próprias afirmações que não ensinam a técnica?

Entendemos que a "técnica" indesejável, a que cada um desses autores se refere nos seus comentários, é a técnica que não mantém uma relação efetiva com a espontaneidade.

Para Grotowski, no Teatro Laboratório, na Polônia, entre 1959 a 1969 (a chamada "fase de espetáculos”), os atores faziam exercícios para desenvolver um alto nível de habilidade física e vocal, mas o simples desenvolvimento dessas habilidades não era o objetivo principal do treinamento. Os atores usavam os exercícios como ferramentas no processo de "liberar" o corpo, 
ou seja, a técnica servia ao "caminho negativo" de eliminar bloqueios. De acordo com Grotowski, os exercícios técnicos foram usados para confrontar o ator com o desafio de fazer algo “impossível”, o qual exigia a descoberta e a eliminação dos bloqueios físicos e psicológicos que dificultavam a realização do exercício (Grotowski, 1969, p.174-175). Nesse contexto, os exercícios serviam como uma exploração da relação entre a espontaneidade e a precisão técnica. Grotowski explicava:

Finalmente, depois de ter aplicado diferentes tipos de exercícios plásticos extraídos de sistemas bem conhecidos (Delsarte, Dalcroze e outros), passo a passo, começamos a considerar esses exercícios plásticos como uma conjuntio oppositorum entre estrutura e espontaneidade. Nos movimentos do corpo existem formas fixadas, detalhes que podem ser chamados de formas. A primeira coisa essencial é fixar um certo número desses detalhes e torná-los precisos. Depois, reencontrar os impulsos pessoais que podem encarnar esses detalhes; ao dizer encarnar, entendo: transformá-los. (Grotowski, 1969, p.171)

Mais adiante, continua:

Liberamos a semente: entre as margens dos detalhes passa agora o "rio das nossas vidas". Espontaneidade e disciplina ao mesmo tempo. Isso é decisivo. Dizer que se trata de uma conjuntio oppositorum entre espontaneidade e disciplina ou, antes, entre espontaneidade e estrutura, ou em outras palavras ainda, entre espontaneidade e precisão, seria um pouco como usar uma formula árida, calculada. No entanto, do ponto de vista objetivo, é precisamente isso. (Grotowski, 1969, p.174)

Observamos, então, que a relação entre a técnica e a espontaneidade é um elemento essencial na obra de Grotowski, no sentido de que a precisão da técnica física serve como a estrutura para reencontrar os impulsos pessoais do ator. A estrutura das formas físicas fixas, repetidas pelo ator, estabelecia limites ao exercício livre da espontaneidade, criando uma tensão que potencializava a expressividade do ator. Constatamos isto nos comentários de Ludwik Flaszen, o parceiro de Grotowski no Teatro Laboratório. Com referência ao trabalho do Grotowski, Flaszen diz:

\footnotetext{
"A união (em uma versão diferente: a dialética) de espontaneidade e disciplina": essa fórmula famosa tem um sentido rigorosamente técnico. $\mathrm{O}$ ato do ator compõe-se das reações vivas do seu organismo, da "corrente dos impulsos visíveis" no corpo. Todavia, para que esse processo orgânico não se desvie no caos, é necessária a estrutura que o canalize, a partitura composta do movimento e do som. Essa presença simultânea de dois elementos opostos favorece a tensão interior que potencializa a expressividade do ator. Espontaneidade, disciplina - nessas palavras podemos chegar a sentir também máximas de vida ou princípios éticos. (Flaszen, 2001, p.30)
} 
Thomas Richards, o aprendiz de Grotowski, que trabalhava com o mestre na última fase da sua obra, em Pontedera, na Itália, faz uma afirmação semelhante sobre a importância da relação entre a precisão e a espontaneidade (Richards, 1995, p.21). Richards escreve sobre:

\begin{abstract}
...os dois polos que emprestam a uma performance o seu equilíbrio e substância: forma de um lado, e fluxo de vida no outro; as duas margens do rio que permitem que o rio corra. Sem essas margens, haverá apenas um alagamento, um pântano. Isto é o paradoxo do artesanato de interpretação: somente pela luta entre essas duas forças antagônicas será possível que o equilíbrio da vida cênica apareça (Richards, 1995, p.21).
\end{abstract}

Isto indica que Grotowski afirmava a importância dessa relação entre a técnica e a espontaneidade na primeira e na última fase do seu trabalho.

A mesma afirmação pode ser vista nas publicações de Spolin e em Linklater também. De acordo com Spolin, o ator aprende pela experiência própria, pela exploração do ambiente imediato e pela reação espontânea às circunstâncias específicas de cada momento (Spolin, 1998, p.3-6). Assim, ela argumenta que o educador precisa gerar condições para exigir reações espontâneas do sujeito e que, nesses momentos de espontaneidade, o sujeito escolhe intuitivamente as melhores soluções para resolver qualquer problema cênico, aprendendo, assim, por meio da própria experiência.

Para Spolin, então, a "espontaneidade" é a condição essencial para adquirir a técnica. Nesse sentido, ela defende que o "jogo" é o processo natural para criar o ambiente propício para induzir essa mesma espontaneidade (Spolin, 1998, p.5). Ela escreve:

\begin{abstract}
O objetivo no qual o jogador deve constantemente concentrar e para o qual toda a ação deve ser dirigida provoca espontaneidade. Nessa espontaneidade, a liberdade pessoal é liberada, e a pessoa como um todo é física, intelectual e intuitivamente despertada. Isto causa estimulação suficiente para que o aluno transcenda a si mesmo - ele é libertado para penetrar no ambiente, explorar, aventurar e enfrentar sem medo todos os perigos. A energia liberada para resolver o problema, sendo restringida pelas regras do jogo e estabelecida pela decisão grupal, cria uma explosão - ou espontaneidade - e, como é comum nas explosões, tudo é destruído, rearranjado, desbloqueado. (Spolin, 1998, p.5)
\end{abstract}

Portanto, Spolin repete a afirmação da importância da técnica sob a condição de que seja desenvolvida em conjunto com a espontaneidade. Porém, à princípio, observamos uma inversão de ordem no sentido de que, para Grotowski, a precisão técnica da partitura física/vocal é a condição necessária para provocar a espontaneidade, enquanto, para Spolin, a reação espontânea no jogo é a condição necessária para desenvolver as técnicas teatrais. Este contraste explica diferenças na forma do trabalho dos dois autores: a estrutura altamente definida em termos de marcações de movimento e voz no trabalho de Grotowski, em contraste com a forma mais aberta do jogo da 
Spolin. No entanto, entendemos essas diferenças como diferenças de grau e não de substância, uma vez que a estrutura permanece como o pré-requisito para os dois.

Para Grotowski, a estrutura dá-se pela forma da partitura física/vocal do ator, enquanto para Spolin, a estrutura se dá pela regra do jogo. No caso da Spolin, a estrutura não depende necessariamente da técnica física/vocal do ator, mas ainda é essencial à libertação da espontaneidade, não importa a forma em que é colocada. Neste sentido, Ingrid Koudela, discutindo a obra da Spolin, avisa que "ação espontânea não equivale simplesmente a ação livre" (Koudela, 2006; p.51). Spolin reconhece este paradoxo dentro do qual o ator trabalha, colocando a pergunta: "como um modo de ação "planejado" pode ser ao mesmo tempo "livre"?" (Spolin, 1998, p.18). Em resposta a esta pergunta, ela afirma: “são as exigências da própria forma de arte que devem nos apontar o caminho, moldando e regulando nosso trabalho, e remodelando a nós mesmos para enfrentar o impacto desse grande força” (Spolin, 1998, p.18).

Dentro desse contexto, se entendermos a repetição de certos movimentos de corpo e voz como uma espécie de "jogo", os paralelos entre o trabalho de Grotowski e o trabalho de Linklater ficam mais evidentes. Com este pensamento, observamos que Spolin até propõe jogos de repetição visando à marcação cada vez mais precisa do trabalho do ator. Ela propõe, por exemplo, o jogo “Começo e Fim", no qual, depois de realizar uma improvisação, o ator volta para "desmembrar a pequena cena em uma série de cenas menores, ou "pulsações"”, (Spolin, 1998, p.121). O ator marca as divisões, fazendo uma pausa para declamar "começo" e "fim”". Spolin sugere como exemplo:

O jogador entra (COMEÇO). Olha em torno para assegurar-se de que não há ninguém e finalmente fecha a porta (FIM). (COMEÇO) Permanece em pé e olha em torno, vê o armário e vai até ele (FIM). (COMEÇO) Abre algumas gavetas, remexe as roupas, acha que ouviu alguma coisa, rapidamente fecha as gavetas e volta para a porta para escutar (FIM)... (Spolin, 1998, p.121).

Observamos, nesse exemplo, que Spolin está descrevendo uma forma de marcação de partitura, ainda bem aberta. Podemos entender que quanto mais o ator divide as ações e acrescenta detalhes, tanto mais se aproxima da precisão defendida por Grotowski. Spolin comenta sobre esse jogo dizendo que "em quase todos os casos, descobrimos que a cena final tinha mais vida, tanto para o ator como para a plateia. Isto se verifica porque a primeira cena tendia a ser generalizante, ou o jogador estava envolvido subjetivamente, usando invenção em lugar de criação" (Spolin, 1998, p.122).

Dessa forma, podemos entender a partitura de Grotowski como um tipo de jogo no qual a espontaneidade se desenvolve conjuntamente com a precisão da técnica física/vocal. Enquanto isso, a descrição do jogo de Spolin, “Começo e Fim”, destaca, para nós, que dentro de cada marcação, o 
ator continua jogando livremente para explorar a trama do momento. Esta liberdade não deve ser inibida pelo acréscimo de detalhes, e sim, direcionada e canalizada cada vez mais. Lembramo-nos da metáfora proposta por Richards, que repetimos agora para enfatizar: existe "forma de um lado, e fluxo de vida no outro; as duas margens do rio que permitem que o rio corresse" (Richards, 1995, p.21).

Uma terceira referência que acrescentamos à análise dessa questão é Kristin Linklater, que também apresenta uma obra distinta, mas que ainda compartilha princípios comuns com o trabalho de Spolin e de Grotowski. De acordo com eles, Linklater trata a ideia de "técnica" com cuidado, mas afirma sua importância em relação à espontaneidade. Para Linklater, a espontaneidade é bloqueada por automatismos que atrapalham o funcionamento eficiente do sistema sensório-motor, cortando a ligação entre impulso interior e ação. Esta preocupação com a conexão entre o impulso e a ação já nos alerta para comparações importantes com a obra de Grotowski. Linklater fala:

\footnotetext{
A voz é impedida de responder com a espontaneidade... porque a espontaneidade depende de uma ação reflexa e a maioria das pessoas tem perdida a habilidade e talvez o desejo de agir de acordo com os reflexos. Exceto em momentos nos quais se esteja "fora de controle", como, por exemplo, em momentos de dor intensa, medo intenso ou prazer intenso, impulsos secundários causam curtos-circuitos em quase todas as ações reflexas. Esses, em geral, são para proteção e, no melhor caso, proporcionam um tempo breve para pensar. Quando, porém, os impulsos secundários são tão bem desenvolvidos que apagam o impacto do impulso primário ou impulso reflexo, um hábito se formou (Linklater, 1976; p.11).
}

Linklater coloca que os impulsos reflexos são inibidos por impulsos secundários, os quais usam o sistema motor voluntário para inibir e controlar o funcionamento espontâneo do aparelho vocal, e que, eventualmente, esses modos de controle voluntário tornam-se hábitos, restringindo a capacidade natural do indivíduo de comunicar-se espontaneamente (Linklater, 1976, p.12). Linklater cita a influência de Moshe Feldenkrais no seu trabalho (Linklater, 1976, p.20), que também levanta a questão de que muitas ações reflexas podem ser inibidas e controladas pelo sistema motor voluntário, e à medida que esses impulsos secundários de controle tornam-se habituais, eles começam a funcionar "independente da nossa intenção, e quando são praticamente automáticos passam por menos transmissores e adquirem uma velocidade comparável com movimentos reflexos" (Feldenkrais, 1992, p.23).

Esses comentários são importantes para nossa discussão, na medida em que sugerem que a verdadeira espontaneidade é impossível enquanto o sistema sensório-motor não for liberado de automatismos ineficientes. De acordo com esta visão, o sujeito pode ser limitado por hábitos físicos e psicológicos e dessa maneira condicionado a repetir certos padrões, tanto na vida quanto na arte, até que esses hábitos sejam revelados e superados. Dessa maneira, Linklater propõe um trabalho de 
consciência corporal para possibilitar a reaprendizagem do modo de usar o corpo, a voz, a imaginação e o pensamento. Nesse processo, então, a aprimoramento da técnica corporal é o caminho para liberar a espontaneidade.

Assim, destacamos uma diferença entre a obra de Linklater e a de Spolin, no sentido de que, para Linklater, à primeira vista, a afinação da técnica corporal antecede a ação espontânea, enquanto para Spolin, a ação espontânea é o meio de adquirir a técnica. Porém, como na comparação com a obra de Grotowski, entendemos esses contrastes como diferenças de abordagem e de foco, mas não de princípio diante da relação entre técnica e espontaneidade.

O foco da Spolin é mais abrangente do que o da Linklater, no sentido de que Spolin aborda as técnicas de interpretação em geral, e não somente a técnica vocal; mas mesmo assim, ela não nega a importância desta, mostrando uma preocupação constante com o corpo, e até sugerindo sequências de jogos direcionados ao desenvolvimento da técnica vocal como, por exemplo, os jogos para "agilidade verbal" (Spolin, 1998, p.161) e os jogos de "dicção" (Spolin, 1998, p.175). A abordagem da Spolin, porém, é sempre sobre o jogo teatral, enquanto o trabalho da Linklater envolve, em grande parte, uma exploração pessoal do corpo e sua funcionalidade.

Mesmo assim, Linklater não nega a importância do jogo e o usa no seu trabalho, embora de maneira diferente de utilizada por Spolin. Linklater, por exemplo, propõe exercícios com sons infantis e estimula a exploração da boca com os dedos, fazendo a recomendação de que o sujeito “reverta a um estado berçário de brincar com sons entre o dedo, os lábios e os dentes" (Linklater, 1976, p.43), e assim, ela promove um tipo de “jogo sensório-motor”, típico de bebês nos primeiros anos da vida. Além disso, Linklater apresenta exercícios que envolvem o "jogo lúdico", típico de crianças entre os dois até onze anos de vida. Ela trabalha com imagens lúdicas, pedindo, por exemplo, que o sujeito imagine que "as pontas dos dedos flutuam até o teto" (Linklater, 1976, p22), ou, em outro momento, sugerindo que o sujeito é "um torso ereto sem cabeça" (Linklater, 1976, p. 23). Mais adiante, ela utiliza o jogo dramático pessoal, também, pedindo, por exemplo, que o sujeito crie cores (Linklater, 1976, p.80-81) e desenhos (Linklater, 1976, p.140) com a voz. Dessa forma, o sujeito usa o som como símbolo, substituindo uma coisa concreta pela ação física/vocal.

Ingrid Koudela descreve o sistema de jogos teatrais, de Spolin, como uma fusão entre o jogo lúdico e o jogo de regras (Koudela, 2006, p.38). Em comparação, aspectos do trabalho de Linklater poderiam ser caracterizados como uma fusão entre o jogo sensório-motor e o jogo lúdico. Nesse caso, o tipo de jogo no qual Linklater se inspira é diferente do "jogo de regras” que inspira Spolin, mas nos dois casos há uma recorrência aos jogos naturais da criança em desenvolvimento para estimular a exploração espontânea da técnica. Assim, voltamos ao mesmo princípio, que a técnica se desenvolve em conjunto com a espontaneidade. 
Evidentemente, há grandes diferenças entre as obras dos três autores principais, citados aqui. Apesar da concordância sobre a relação entre técnica e espontaneidade, eles demonstram uma divergência grande em relação às estratégias elaboradas para ensinar a técnica na prática. Mas essas diferenças permitem destacar a relevância abrangente dos pensamentos compartilhados sobre técnica, espontaneidade e criatividade. O objetivo maior desta pesquisa de doutorado é aprofundar o estudo das comparações, das semelhanças e contrastes entre esses três autores, para elaborar uma base conceitual que contribua à construção do conhecimento sobre a técnica, a espontaneidade e a criatividade, para direcionar a construção de novas práticas de ensino/aprendizagem da técnica vocal para o teatro. 


\section{Bibliografia:}

BARBA, Eugênio e SARAVESE, Nicola. A Arte Secreta do Ator: o Dicionário de Antropologia Teatral. São Paulo-Campinas: Editora UCITEC, editora do UNICAMP, 1995.

FLASZEN, Ludwik. De Mistério a Mistério: Algumas Observações em Abertura. 2011 Em FLASZEN Ludwik e POLLASTRELLI, Carla (curadoria) O Teatro Laboratório de Jerzy Grotowski 1959 - 1969: textos e materiais de Jerzy Grotowski e Ludwik Flaszen com um escrito de Eugênio Barba. São Paulo: Perspectiva: SESC; Pontadera, IT. Fundazione Pontadera Teatro, 2007. GROTOWSKI, Jerzy. Em Busca de um Teatro Pobre. $4^{a}$ ed. Rio de Janeiro: Editora Civilização Brasileira, 1992.

(1969) Exercícios, 1969. Em FLASZEN Ludwik e POLLASTRELLI, Carla (curadoria) O Teatro Laboratório de Jerzy Grotowski 1959 - 1969: textos e materiais de Jerzy Grotowski e Ludwik Flaszen com um escrito de Eugênio Barba. São Paulo: Perspectiva: SESC; Pontadera, IT. Fundazione Pontadera Teatro, 2007.

LINKLATER, Kristin. Freeing Shakespeare's Voice: the actor's guide to talking the text. $1^{\text {st }}$ Ed. New York: Theatre Communications Group, 1992

FELDENKRAIS, Moshé. The Potent Self: a guide to spontaneity. 1st Ed. New York: Harper and Collins Publishers, 1992.

KOUDELA, Ingrid Dormien. Jogos Teatrais $5^{\mathrm{a}}$ ed. São Paulo: Perspectiva, 2006.

RICHARDS, Thomas. At Work With Grotowski on Physical Actions. London: Routledge, 1995.

SPOLIN, Viola. Improvisação para o Teatro. $4^{\mathrm{a}}$ ed. São Paulo: Perspectiva, 1998.

Observação: Os textos dos seguintes autores, incluídos como citações, foram traduzidos pelo autor dessa Tese: Feldenkrais, 1992; Linklater, 1976; Richards, 1995.

\footnotetext{
'Faremos referência especificamente à primeira e a última fase da obra de Grotowski, isto é, a "fase de espetáculos", no Teatro Laboratório, na Polônia, entre 1959 a 1969, e a fase de "arte como veículo", no Workcenter de Jerzy Grotowski e Thomas Richards, na Itália, de 1986 até o falecimento do mestre polonês, em 1999.

ii Esta citação de Grotowski, no original, está destacada em itálico, mostrando a importância do seu sentido para o autor.
} 